\title{
Preparation of Silica-Gold Composite particles
}

\author{
Dae-Wook Kim ${ }^{1}$, Seung-Bo Shim ${ }^{1}$ and Yong-Jin Chun ${ }^{2^{*}}$ \\ ${ }^{1}$ Goodseed Cosmetics \\ ${ }^{2}$ Dept. of Cosmetic Science, Chungwoon University \\ 실리카-골드 복합체의 합성 연구 \\ 김대욱 ${ }^{1}$, 심승보 ${ }^{1}$, 전용진 $2^{*}$ \\ ${ }^{1}$ 좋은씨앗, ${ }^{2}$ 청운대학교 화장품과학과
}

\begin{abstract}
Abstrac Silica-gold composite particles were prepared by wet chemical route including impregnation method. The effect of precursor and solvent on the preparation of silica-gold particles was investigated. When spherical silica particles and PVP and hydrogentetrachloroaurate(III) hydrate aqueous solution were used as support material and precursor solution, silica-gold composite particles with light pink color successfully obtained. Obtained composite particles were characterized using FE-SEM, FE-TEM and XRD

요 약 실리카-골드 복합체 입자를 함침법에 의하여 합성하였고, 용매와 전구체가 실리카-골드 입자 합성에 미치는 영향이 연구되었다. 구형 실리카 입자를 지지체로 하여 PVP, hydrogentetrachloroaurate(II) hydrate 수용액을 전구체로 사용했을 때, 연한 분홍색 색상을 띄는 실리카-골드 입자가 성공적으로 합성되었다. 합성된 복합체의 특성은 FE-SEM, $\mathrm{FE}-\mathrm{TEM}$ 과 XRD를 통하여 분석하였다.
\end{abstract}

Key Words : Silica, Gold, Composite particle

\section{Introduction}

Recently, a great deal of attention has been devoted to design and preparation of composite particles with metallic layer because of their applications in various field such as surface-enhanced raman scattering (SERS) [1], photonic crystals [2, 3], catalysis [4] and biochemistry for potential uses as chemical sensors [5], and so on.

In addition, these hybrid materials have outstanding characteristics that distinguish them from conventional bulk and nanophase materials. One of the important problems in most applications of nanoparticles is the aggregation of individual nanoparticles. In powder state, nanoparticles form micron-sized secondary particles adhering to each other during preparation, storage and application. If this occurs, the properties of the materials may be determined by the size of the secondary particles, not by the individual particles. In colloid state, individual nanoparticles can be maintained well-dispersed state by steric hindrance effect or electrostatic repulsion via precise control of the chemical composition and physical properties of the solution. However, well-dispersed colloidal nanoparticles also can easily lose their stability by unexpected variation of solution state during storage and application. These problems can be greatly improved by immobilization of nanoparticles onto the support materials. Moreover, these nanoparticles are easily retrieved owing to the relatively large size of supports. As a result, they make it easy to handle metal nanoparticles, which can decrease the cost of process and prevent the potential environmental pollution caused by undesired spread of the metal nanoparticles.

This work was support by Korea Sanhak Foundation fund, 2011

*Corresponding Author : Yong-Jin Chun(yjchun@chungwoon.ac.kr)

Received October 31, 2011 Revised November 9, $2011 \quad$ Accepted November 10, 2011 
Gold is famous for its anti-aging effect due to their promotion of blood circulation. In this reason, many cosmetic companies have tried to apply gold as an active ingredient for cosmetics. However, the high cost and is a serious limitation of enlargement of gold incorporated cosmetics. Silica-gold composite material can be a strong candidate to overcome these limitations due to their unique characteristic.

Recently, novel preparation routes for composite materials have been proposed to simplify the conventional complex reaction process or to obtain dense and uniform metal layers: sono-chemical deposition [6], electroless plating [7], electrostatic attraction [8] techniques and so on. However these preparation routes have a quite complex process and resulting materials are too expensive to use as a cosmetic raw materials

In this study, we investigated simple and economic preparation route based on impregnation method to make silica-gold composite particles with high yield and economical price. The obtained Silica-gold composite particles were characterized through FE-SEM, FE-TEM and XRD

\section{Experimental}

\subsection{Materials}

Hydrogentetrachloroaurate(III) hydrate $\left(\mathrm{HAuCl}_{4} \bullet \mathrm{nH}_{2} \mathrm{O}, \mathrm{n}\right.$ $=3.7$, Kojima Chemicals), polyvinylpyrrolidone (PVP, K-15, Mw10,000, Junsei Chemical Company ,Japan), Ethanol (Duksan chemicals company) and gold colloid (Quick\&Safe.) were purchased and used. Silica particles was suggested and provided by Quick\&Safe. All materials were used as received.

The water used in this study was deionized by Milli-Q Plus system(Millipore, France), having 18.2M $\Omega$ electrical resistivity.

\subsection{Experimental Procedure}

In typical process, support materials, silica particles, were added into reactants solutions. And then resulting silica particles were centrifuged or dried. Finally, dried silica particles were calcinated in furnace at $500^{\circ} \mathrm{C}$ $700^{\circ} \mathrm{C}$ in 2hours. Experimental conditions are listed in table 1 .

[Table 1] Experimental conditions

\begin{tabular}{|c|c|c|c|}
\hline No 1. & Silica & Solvent & Precursor \\
\hline No 2. & B type & Water & Gold ions \\
\hline No 3. & B type & Water & $\begin{array}{c}\text { Gold ions, } \\
\text { PVP }\end{array}$ \\
\hline No 4. & B type & Ethanol & $\begin{array}{c}\text { Gold ions } \\
\text { Gold ions, } \\
\text { PVP }\end{array}$ \\
\hline No 5. 6. & B type & Ethanol & $\begin{array}{c}\text { Gold } \\
\text { particles }\end{array}$ \\
\hline
\end{tabular}

\subsection{Characterization}

To investigate formation and morphological properties of composite particles, transmission electron microscopy (TEM, JEOL-model JEM-1000EX П) and field emission scanning electron microscopy (FE-SEM, JEOL JSM-6700F) were used. To verify the formation of gold, X-ray diffractometry measurement was performed with a Rigaku D/MAX-3C x-ray diffractometer. The incident wavelength was $\mathrm{Cu} \mathrm{Kal}=1.789 \AA$, and the detector moved step by step $\left(\triangle 2 \Theta=0.05^{\circ}\right)$ between $10^{\circ}$ and $90^{\circ} 2 \theta$. The scan speed was $2 \%$ minute.

\section{Results and discussion}

The morphology of the two kind of silica particles were investigated and compared using FE-SEM as shown in fig. 1 .

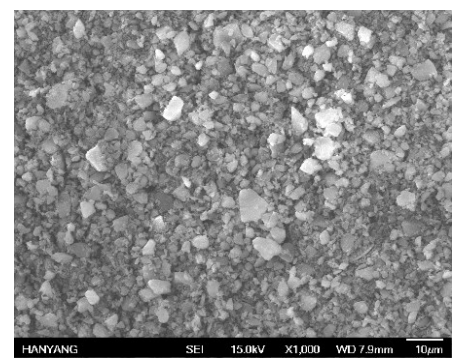

(A) 


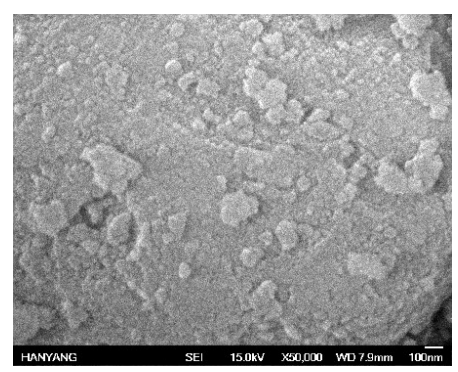

(B)

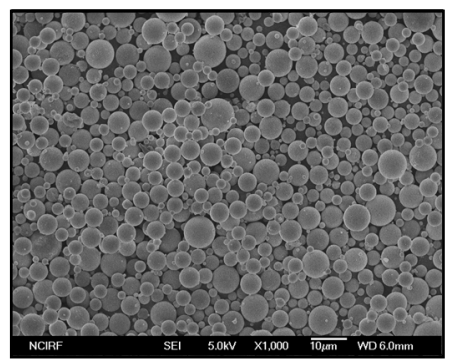

(C)

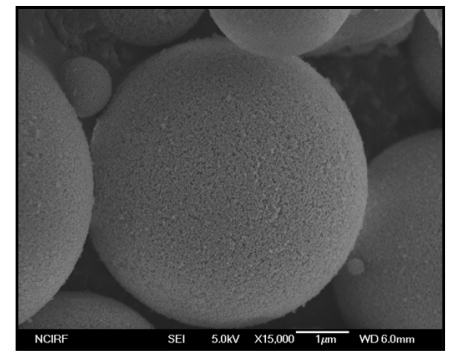

(D)

[Fig. 1] FE-SEM photographs: (A) S type silica particles (X1,000 magnification), (B) $\mathrm{S}$ type (X50,000 magnification), (C) B type silica particles (X1,000 magnification) and (D) B type silica particles (X15,000 magnification)

$S$ type silica particles showed very rough and sharp edged shapes as shown in fig 1.(A) and (B). On the contrary, B type silica consisted of almost perfect sphere shaped individual particles. Average diameter of B type silica particles is determined about $6 \mu \mathrm{m}$. B type particles are better than $\mathrm{S}$ type particles with respect to cosmetic applications because spherical particles with $6 \mu \mathrm{m}$ average diameter scatter light on the surface of its particles, i. e. which are transparent, but give natural coverage of skin and silky feeling.

To prepare silica-gold composite particles using B type silica particles, five experimental conditions were chosen and tested as shown in table 1. No.2 - No.6.
To obtain homogeneous composite particles, the effect of solvent on the formation of silica-gold particles was investigated as shown in table 1.

As water was used as a solvent for impregnation process, resulting composite particles showed homogeneous light yellow color after drying. On the contrary, ethanol solvent gave resulting particles with uneven color, mixed color of light yellow and purple, which is attributed to the fast reduction of gold ions during drying period by redox reaction between ethanol and gold ions.

To investigate the effect of precursor on the formation of silica-gold composite particles, three different precursor conditions were examined: gold ions(No2 in table 1), gold-PVP complexes(No3 in table 1) and gold colloidal particles(No6 in table 1). The concentration of gold in composite particles fixed to $1.0 \%$. The particle size of colloidal particles used in this experiments was below $20 \mathrm{~nm}$ as shown in fig. 2.

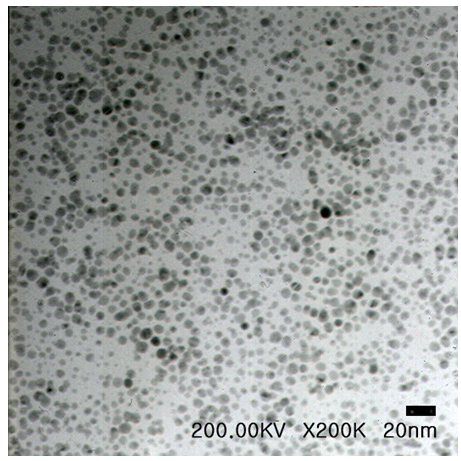

[Fig. 2] FE-TEM photographs of colloidal gold particles

Compare with hydrogentetrachloroaurate(III) hydrate aqueous solution, PVP and hydrogentetrachloroaurate(III) hydrate aqueous solution was used, obtained silica-gold composite particles showed better color reproducibility. Aqueous colloidal gold particles was used as a precursor solution, very deep wine red and deep purple colored silica-gold particles was obtained at calcination temperature of $500^{\circ} \mathrm{C}$ and $700^{\circ} \mathrm{C}$, respectively. It is thought that silica-gold particles prepared using hydrogentetrachloroaurate (III) hydrate aqueous solution and PVP and hydrogentetrachloroaurate(III) hydrate aqueous solution were better than that prepared using aqueous colloidal particles as a cosmetic raw material in the respect of the color of the particles. Figure 3. show the silica-gold 
composite particles obtained using PVP and hydrogentetrachloroaurate(III) hydrate aqueous solution as a precursor.

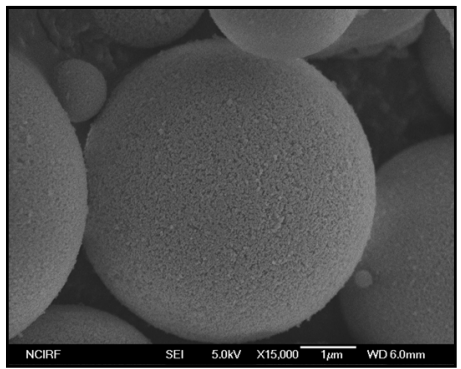

(A)

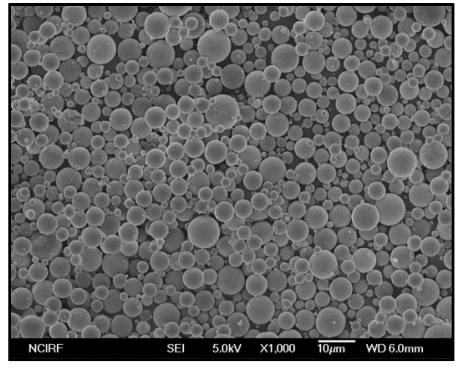

(B)

[Fig. 3] FE-SEM photographs of silica-gold particles (A) $\mathrm{X} 15,000$ magnification and (B) X1,000 magnification

Despite of composite formation, silica particles maintained the spherical shape.

To verify the formation of silica-gold composite particles, resulting powders were examined using XRD as shown in fig. 4.

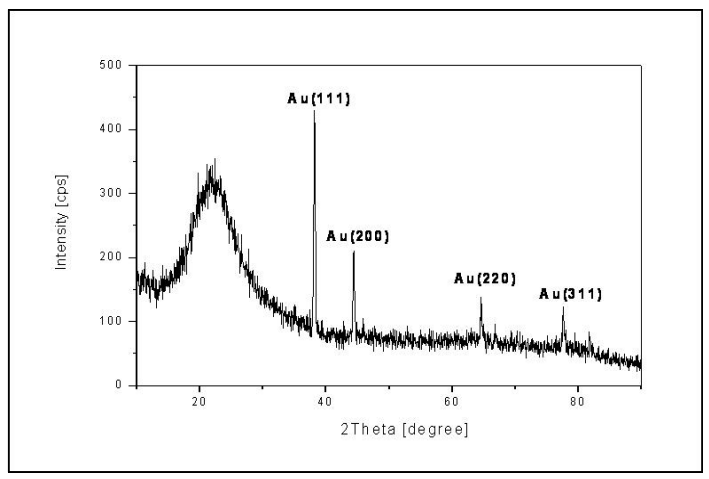

(A)

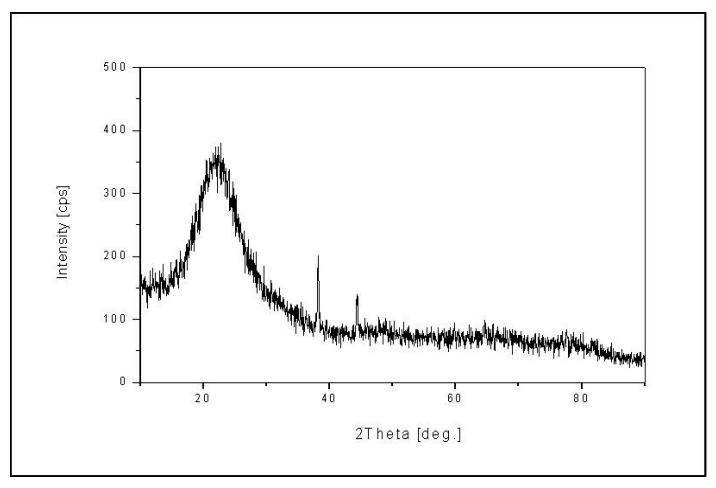

(B)

[Fig. 4] XPD patterns of silica-gold particles loaded (A) $1 \%$ gold and (B) $0.5 \%$ gold

Fig. 4(A) verifies the amorphous silica-gold composite particle formation. When the loading amount of gold decrease from $1 \%$ to $0.5 \%$, the characteristic peak of gold also decreased.

\section{Conclusions}

Silica-gold composite particles were prepared by wet chemical method including impregnation method. When spherical silica particles and PVP and hydrogentetrachloroaurate (III) hydrate aqueous solution was used as support material and precursor solution, silica-gold composite particles with light pink color successfully obtained.

\section{References}

[1] A. Campion, P. Kambhampati, Chem. Soc. Rev. 27 (1998) 241

[2] Z. L. Wang, C. T. Chan, W. Y. Zhang, Z. Chen, N. B. Ming, and P. Sheng, Phys. Rev. B 64 (2001) 113108

[3] (a) D. Wang, V. Salgueiriño-Maceira, L. M. Liz-Marzán, and F. Caruso, Adv. Mater. 14 (2002) 908 (b) Z. Liang, A. S. Susha, and F. Caruso, Adv. Mater. 14 (2002) 1160

[4] C. W. Chen, T. Serizawa, and M. Akashi, Chem. Mater. 11 (1999) 1381 (b) S. Phadtare, A. Kumar, V. P. Vinod, C. Dash, D. V. Palaskar, M. Rao, P. G. Shukla, S. Sivaram, and M. Sastry, Chem. Mater. 15 (2003) 1944 (c) Z. J. Jiang, C. Y. Liu, and L. W. Sun, J. Phys. 
Chem. B 109 (2005) 1730

[5] S. A. Kalele, S. S. Ashtaputre, N. Y. Hebalkar, S. W. Gosavi, D. N. Deobagkar, D. D. Deobagkar, and S. K. Kulkarni, Chem. Phys. Lett. 404 (2005) 136

[6] V.G.Pol, A. Gedanken, J. Calderon-Moreno, Chem. Mater. 15 (2003) 1111.

[7] Y. Kobayashi, Y. Tadaki, D. Nagao, M. Konno, J. colloid Interface Sci. 283 (2005) 601

[8] J. Zhang, J. Liu, S. Wang, P. Zhan, Z. Wang, M. Ming, Adv. Funct. Mater. 14 (2004) 1089

\section{Dae-wook Kim}

[Regular member]

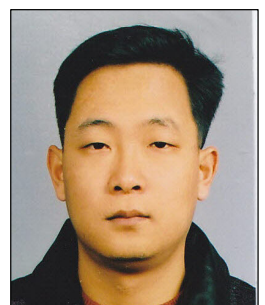

- Feb. 2000 : Dept. of Chemical Eng. Hanyang University(M.S)

- Feb. 2006 : Dept. of Chemical Eng. Hanyang University(Ph.D)

- Mar. $2009 \sim$ current : Goodseed Cosemtics General Manger

$<$ Research Interests $>$

Cosmetics, Natural substance, NT, BT

\section{Seung-bo Shim}

[Regular member]

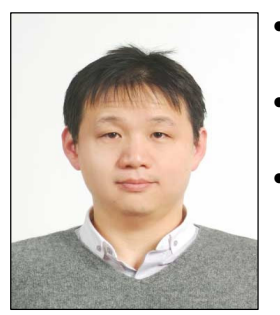

- Feb. 2000 : Dept. of Chemistry Soongsil Uni.versity(M.S)

- Feb. 2012 : Dept. of Chemical Eng. Hanyang University(Ph.D)

- Mar. $2008 \sim$ current : Goodseed Cosemtics President
Yong-Jin Chun

[Life member]

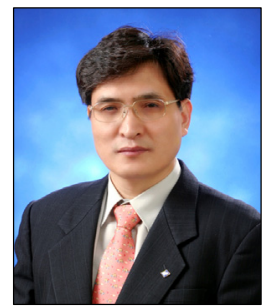

- Feb. 1994 : Dept, of Chemical Eng. Korea University(Ph.D)

- Jul. $1986 \sim$ Feb. 1994 : Dept. Chemistry KIST, TBL Center Researcher

- Mar. $1997 \sim$ current : Professor in Dept. Cosmetic Science

$<$ Research Interests $>$

Organic synthesis, Natural product, NT, Cosmetics

$<$ Research Interests $>$

Cosmetics, Natural substance, NT, BT 